\title{
Spectral reflectance properties of iridescent pierid butterfly wings
}

\author{
Bodo D. Wilts · Primož Pirih $\cdot$ Doekele G. Stavenga
}

Received: 7 January 2011/Revised: 5 February 2011/Accepted: 8 February 2011/Published online: 23 February 2011

(C) The Author(s) 2011. This article is published with open access at Springerlink.com

\begin{abstract}
The wings of most pierid butterflies exhibit a main, pigmentary colouration: white, yellow or orange. The males of many species have in restricted areas of the wing upper sides a distinct structural colouration, which is created by stacks of lamellae in the ridges of the wing scales, resulting in iridescence. The amplitude of the reflectance is proportional to the number of lamellae in the ridge stacks. The angle-dependent peak wavelength of the observed iridescence is in agreement with classical multilayer theory. The iridescence is virtually always in the ultraviolet wavelength range, but some species have a blue-peaking iridescence. The spectral properties of the pigmentary and structural colourations are presumably tuned to the spectral sensitivities of the butterflies' photoreceptors.
\end{abstract}

Keywords Pieridae - Multilayers - Iridescence ·

Reflectance $\cdot$ Pterins

\section{Introduction}

Butterflies are among the most colourful terrestrial beings. Their colouration and patterning of the wings can function for display and/or for concealment (Nijhout 1991), and

B. D. Wilts $(\bowtie) \cdot$ P. Pirih · D. G. Stavenga

Department of Neurobiophysics, University of Groningen, Nijenborgh 4, 9747 AG Groningen, The Netherlands

e-mail: b.d.wilts@rug.nl

B. D. Wilts

Department of Applied Physics, Zernike Institute for Advanced

Materials, University of Groningen, Nijenborgh 4,

9747 AG Groningen, The Netherlands where the colouration is sex-specific, it can serve for intersexual recognition (Kemp et al. 2005; Rutowski et al. 2007a, b; Giraldo 2008; Meadows et al. 2009). The two main colouration mechanisms, pigmentary and structural, often simultaneously contribute to the wing colouration (Vukusic and Sambles 2003; Kinoshita et al. 2008). Pigmentary (or chemical) colouration is due to pigments that selectively absorb light in a restricted wavelength range. Structural (or physical) colouration is due to interference of light scattered in nanostructured wing elements.

The colouration pattern of butterfly wings is due to the tapestry of scales, where each scale often has a unique colour. A scale commonly consists of two laminae; a lower lamina, which is approximately flat and solid, and an upper, more elaborate, lamina. The upper lamina is structured by parallel, longitudinal folds, the ridges, which are connected by orthogonal struts, the crossribs (Ghiradella 2010). The ridges are composed of lamellae and feature socalled microribs. The lower and upper laminae are joined by pillar-like trabeculae (Ghiradella 1998; Vukusic et al. 2000).

The components of the upper lamina, i.e. the ridges and crossribs, are often rather irregularly organized, so that in the absence of absorbing pigments the scattering of incident light is wavelength independent, resulting in a white scale colour (Mason 1926; Gilbert et al. 1988; Stavenga et al. 2010). In the presence of pigments that absorb in a restricted wavelength range, the wavelength-selective suppression of scattered light results in coloured wings. The pigments colouring the wings of pierid butterflies are the pterins. The main pterins are leucopterin, xanthopterin and erythropterin. Leucopterin is commonly present in the wings of cabbage butterflies (Yagi 1954). These wings are white, because leucopterin absorbs exclusively in the ultraviolet. However, the wings are distinctly coloured for 
the butterflies themselves, because they have ultravioletsensitive photoreceptors (Arikawa et al. 2005). Xanthopterin and erythropterin absorb up into the blue and green wavelength ranges, respectively, and thus colour the wings yellow and orange or red (Descimon 1975; Morehouse et al. 2007; Wijnen et al. 2007). Interestingly, the pterin pigments are deposited in small pigment granules that enhance the reflectance in the long wavelength range by increased scattering, thus creating a brighter wing colour (Stavenga et al. 2004, 2006; Morehouse et al. 2007).

When the scale components have a regular, periodic arrangement, structural colours arise. The structural colouration of pierids is located in the so-called cover scales, where the ridge lamellae are elaborated into a multilayered structure, which creates an iridescent colouration (Ghiradella et al. 1972; Ghiradella 1989). The scale modification is classified as the Morpho-type (Ghiradella 1998; Vukusic et al. 2000) after the striking, in cross-section, Christmas-tree-like structures that are encountered in the scale ridges on the upper side of the wings of the neotropical genus Morpho. In most Morpho species, illumination of the upper wings with white light creates a blue iridescence, but the iridescent, structural colour of most pierid species virtually always peaks in the ultraviolet wavelength range. In the wings of Morpho's, the iridescent colours are usually intensified by a basal layer of strongly light-absorbing melanin pigments (Vukusic et al. 1999; Kinoshita et al. 2002; Stavenga et al. 2009; Vukusic and Stavenga 2009). A similar intensification of the iridescence is realized in pierid wings by the short-wavelengthabsorbing pterins.

The distribution of iridescence in the wings of pierids varies among the species. Commonly iridescence is restricted to the males, but in some species also females are iridescent. In members of the subfamily Coliadinae, parts of both the forewing and hindwing may be iridescent (Kemp et al. 2005; Rutowski et al. 2005, 2007a, b; Kemp and Rutowski 2007). In the Colotis group, belonging to the subfamily Pierinae, but evolutionarily closest to the Coliadinae (Braby et al. 2006), iridescence is co-localized and literally superimposed on the pigmentary colouration in the tips of the forewings (Stavenga et al. 2006; Stavenga and Arikawa 2006). However, among the different butterflies of the pierid family little is known of the interplay of the structural and pigmentary colours and specifically of their role in signalling. In order to gain understanding into the topic, we have initiated a comparative study of iridescent pierids. Here, we compare the males of two Gonepteryx species, the Cleopatra Brimstone (G. cleopatra) and the Common Brimstone (G. rhamni), with two members of the Colotis group, the Great Orange Tip (Hebomoia glaucippe) and the Queen Purple Tip (Colotis regina). We particularly consider the structure and colouration of single scales. We applied scanning electron microscopy (SEM), to determine their ultrastructure, and (micro)spectrophotometry, to characterize the spectral properties of the wing scales. We found that the scale structures vary among different pierid species and that the iridescence, i.e. the dependence of the colouration on the angle of illumination, can be well understood with the interference condition for multiple layers.

\section{Materials and methods}

Animals

Specimens of G. cleopatra were caught near Argelliers (France), G. rhamni in Groningen (the Netherlands) and around Ljubljana (Slovenia), Hebomoia glaucippe in Taiwan; Colotis regina was obtained from the RMCA (Tervuren, Belgium). Small pieces were cut from the wings using a razor blade and fine scissors. Single scales or wing patches were glued to the tip of a glass micropipette as described previously (Wilts et al. 2009).

\section{Photography}

Samples were photographed using a Nikon D70 MkI camera equipped with an F70 macro objective and a UVfilter (combined Schott glasses UG3 and BG17). Details of the scale arrangement on the wings and single scales were photographed with a Zeiss Universalmikroskop equipped with dark-field optics and a Kappa DX-40 digital camera.

\section{Spectrometry}

Reflectance spectra of the wings were measured with an integrating sphere, with a bifurcated probe, and with an angle-dependent reflectance measurement setup (ARMs). We used an Avantes USB1 or USB2 spectrometer (range $180-1,100 \mathrm{~nm}$ ) equipped with full quartz optics and fibres and a diffuse white reference standard (Avantes WS-2). The light source was a deuterium-halogen lamp or a xenon arc lamp. Reflectance spectra of single scales were measured with a microspectrophotometer (MSP) consisting of a Leitz Ortholux microscope connected with an Avantes spectrometer. The objective was an Olympus $20 \times$ (NA 0.46 ) (for further methods details, see for instance Vukusic and Stavenga 2009).

Scanning electron microscopy

A Philips XL-30 ESEM was used for SEM. Prior to observation, samples were sputtered with a thin layer of 
palladium or gold to prevent charging. For structural analysis of each species, layer thickness and periodicity were measured at minimally ten different spots of different electron micrographs.

\section{Results}

We investigated four pierid species where the males have a prominent structural colouration: G. cleopatra, G. rhamni, Hebomoia glaucippe and Colotis regina. The upper sides of the forewings as well as the hindwings of G. cleopatra and G. rhamni have a main yellow colour (Fig. 1a, b, left column), due to the presence of the pterin pigment xanthopterin, but a large part of the forewings of G. cleopatra is orange coloured, due to erythopterin (Wijnen et al. 2007). The hindwings of both Gonepteryx species have small orange spots. The wings also exhibit a distinct shortwavelength reflection, restricted to the ultraviolet (UV; Fig. 1a, b, right column), which in G. cleopatra is spread out over both forewings and hindwings, but in G. rhamni is restricted to the forewings. The forewings and hindwings of the other two species, $H$. glaucippe and C. regina, are mainly white, due to the presence of leucopterin (Wijnen et al. 2007). The forewings have characteristic, coloured tips; orange and red-purplish, respectively (Fig. 1c, d, left column). The coloured wing tips also reflect strongly ultraviolet and blue light, respectively (Fig. 1c, d, right column).

Whereas the different pigmentary colourations are well understood, the structural colourations have been less well studied, and therefore we investigated the organization and structuring of the wing scales of the different species. Figure 2 shows the scale organization in the forewings of $G$. cleopatra and in the wing tips of $C$. regina as observed with an epi-illumination light microscope. Rows of partly overlapping cover scales overlay the ground scales. The ground scales can only be recognized where the cover scales have dissociated (Fig. 2a, b, white arrowheads). Interestingly, the colour of the cover and ground scales can distinctly differ. In the orange area of the forewings of G. cleopatra, the cover scales are orange, but the ground scales are yellow, like the cover and ground scales in the hindwings. Similarly, in C. regina, the ground scales in the dorsal wing tips are white, like the scales in the main wing area. The cover scales of $C$. regina have a shimmering blue line (Fig. 2b, black arrowheads), which moves when the inspected wing part is rotated under the observation microscope. This indicates that the scales are curved.

We investigated the structural details of the iridescent cover scales by SEM (Fig. 3). The upper side of the scales has densely packed slender longitudinal ridges, which are folded into a stack of lamellae. The scales were slightly flexed to force some of the ridges into side views of the lamellar stacks. The SEM micrographs show that the number of the lamellae varies among the species. Whereas the cover scales of $H$. glaucippe have ridges with 10-12 lamellae (Fig. 3d), in C. regina, the lamellar stack consists of 6-7 layers (Fig. 3e, f). For both these cases, the lamellar stacks run parallel to the scale surface. The number of lamellae in the Gonepteryx species (Fig. 3a-c) is between these extremes (Table 1). Further, the lamellae are tilted with respect to the scale surface. We studied both the forewings and hindwings of G. cleopatra, because reflectance measurements indicated structural differences (see below). Underneath the ridges, a dense layer of pigment granules is seen (Fig. 3d, f).

The organization of the iridescent cover scales and the ground scales appears to be rather different, as shown by the SEM micrograph of two scales in the wing tip of H. glaucippe (Fig. 4). The ridges are much more closely spaced in the cover scales than in the ground scales; the ridge distance is about 0.4 and $0.8 \mu \mathrm{m}$, respectively (Fig. 4a). The lamellae of the cover scale ridges are elaborate but those of the ground scales are inconspicuous. In both the cover and ground scales, the crossribs, which connect the ridges, are adorned with a large number of beads, the pigment granules (Fig. 4a). The open structuring of the scales results in scattering of incident light and, together with the pigments in the granules, thus will determine the colouration. As an example, Fig. 4b shows the reflectance spectrum of the wing tip of $H$. glaucippe, which was measured with a bifurcated probe. The distinct reflectance band in the (ultra)violet wavelength range is caused by the multilayered ridges of the cover scales, acting as an interference reflector. The pigment granules of both the cover and ground scales absorb incident light in the short wavelength range, but at the longer wavelengths the scattered light is not absorbed and the granules then even enhance the light scattering (Fig. 4b). The wavelength-selective pigment absorption and scattering along with wavelength-specific multilayer reflections thus cause the species-characteristic wing colours (Wijnen et al. 2007).

We compared the spectral properties of the structurally coloured wing areas of the studied species by measuring the reflectance spectra from small circular areas (diameter $4 \mathrm{~mm}$ ) with an integrating sphere (Fig. 5). All spectra had a similar appearance; a short-wavelength reflectance band, with a rather variable amplitude, was separated by a reflectance minimum from a high reflectance plateau at long wavelengths, where the reflectance reached a value of about 0.5 . The short-wavelength reflectance bands had a peak wavelength between 340 and $390 \mathrm{~nm}$, except for that of $C$. regina, where the reflectance band peaked near $450 \mathrm{~nm}$ (Fig. 5). 
Fig. 1 Photographs of the upper sides of the wings of four pierid butterfly species; left column RGB; right column UV (ultraviolet). a Gonepteryx cleopatra, b Gonepteryx rhamni, c Hebomoia glaucippe, d Colotis regina. The first three species have wing areas that strongly reflect in the UV. The wing tips of $C$. regina reflect strongly in the blue wavelength range and little in the UV (bars $1 \mathrm{~cm}$ ) a

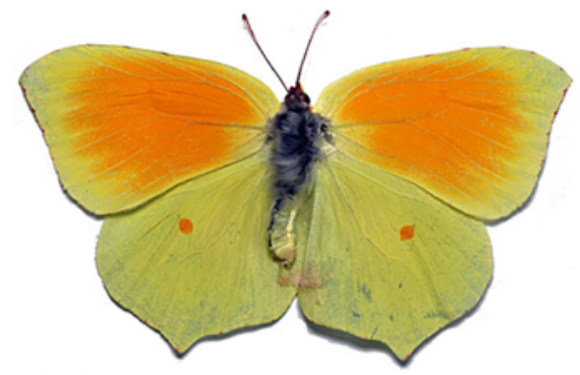

b
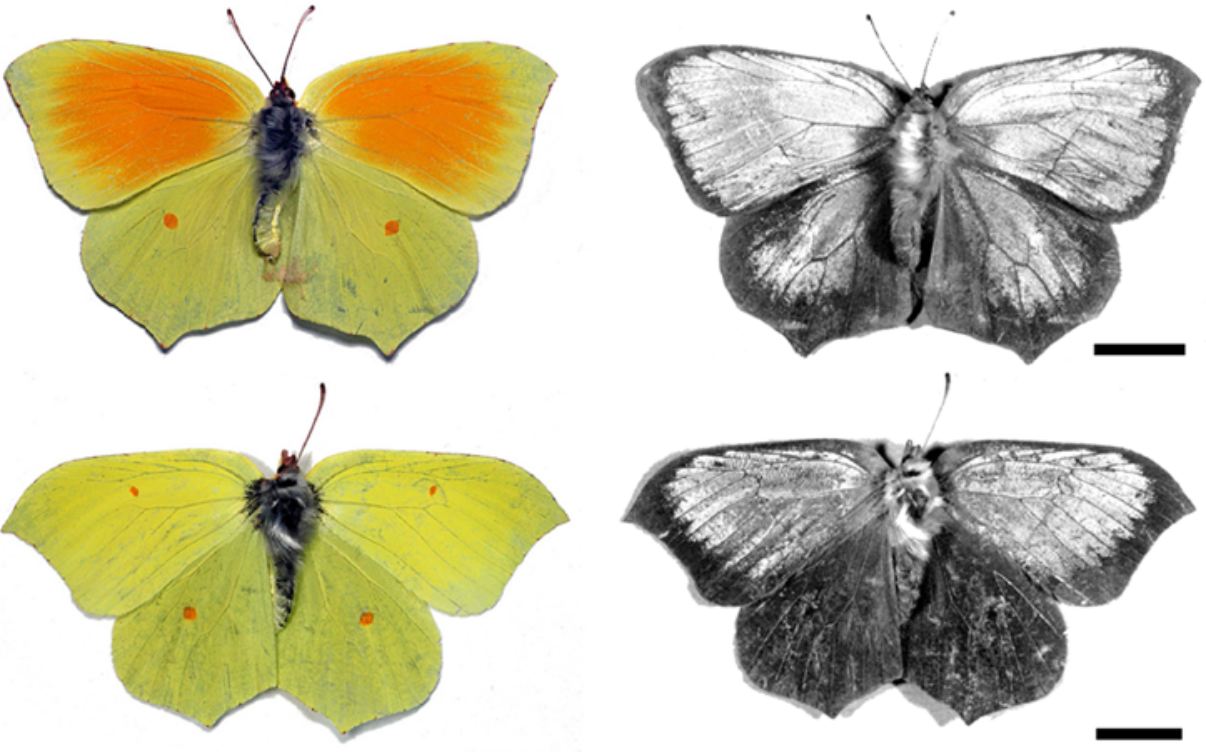

C
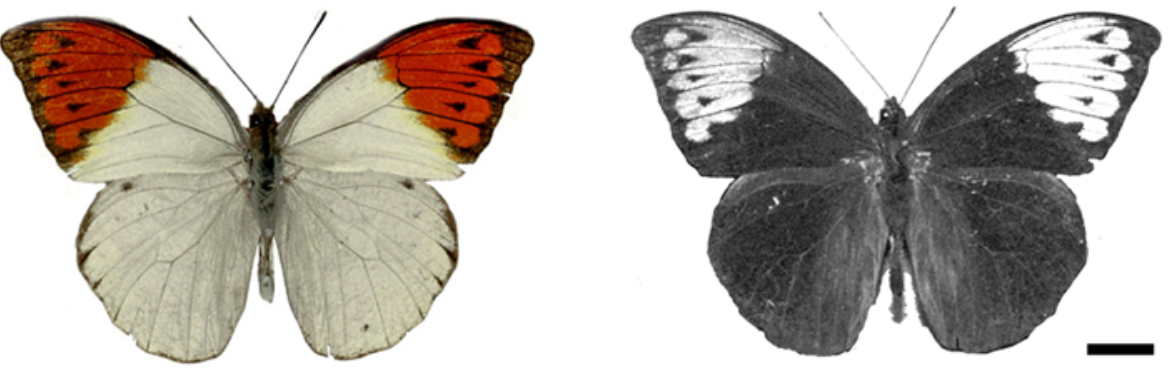

d

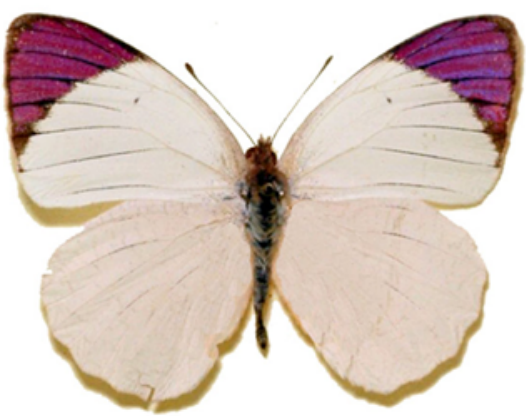

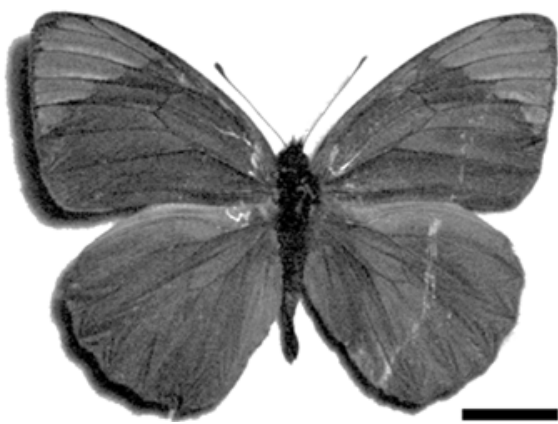

The measured wing reflectance is the cumulative result from both cover and ground scales. To distinguish both contributions, we used a microspectrophotometer to measure the reflectance spectra from individual cover and ground scales in the wing areas with structural colouration of G. cleopatra, H. glaucippe and C. regina (Fig. 6). For comparison, we also measured from scales in adjacent, non-structurally coloured wing areas (Fig. 6b, c). The reflectance of the ground scales was always low at short wavelengths and high at long wavelengths and only the cover scales had an additional reflectance band in the shortwavelength range, and. In $C$. regina (Fig. 6c), the measured ground scale, which was located in the wing tip, embedded in the lattice of cover scales, had a reddish reflection, showing that red light transmitted by the cover scales is partly reflected by the ground scales. In the intact wing, the light transmitted by the cover scales will be reflected by the ground scale and thus will increase the total reflectance signal.

The spectra of Figs. 5 and 6 give only limited information about the reflection properties of the wing scales. In the integrating sphere, the illumination was a narrow beam, hitting the wing approximately normally (beam direction $\sim 8^{\circ}$ off normal), and the integrating sphere integrated the light backscattered into the hemisphere above the wing plane (Fig. 5). In the case of the microspectrophotometer, 
Fig. 2 Organization of the scale array. a Dark-field epiillumination microscopy of the orange area of the forewing of G. cleopatra. A few cover scales are lacking, revealing the yellow ground scales (white arrowhead). b Purple wing tip of $C$. regina. One cover scale is lacking, revealing a ground scale (white arrowhead; bar $100 \mu \mathrm{m})$. Additionally, a blue tinted line is visible on the scales (black arrowheads)

Fig. 3 Scanning electron micrographs of single scales with structural colouration. a G. cleopatra forewing, b G. cleopatra hindwing, c G. rhamni, d H. glaucippe, e $C$. regina, f Sectioned scales of $C$. regina showing that the ridges are folded into a multilayer. A layer with large pigment granules exists beneath the ridges. In a-c the ridges were flexed to show the sideview of the lamellar stack (bars $\mathbf{a}-\mathbf{e}, \mathbf{f} 1 \mu \mathrm{m})$
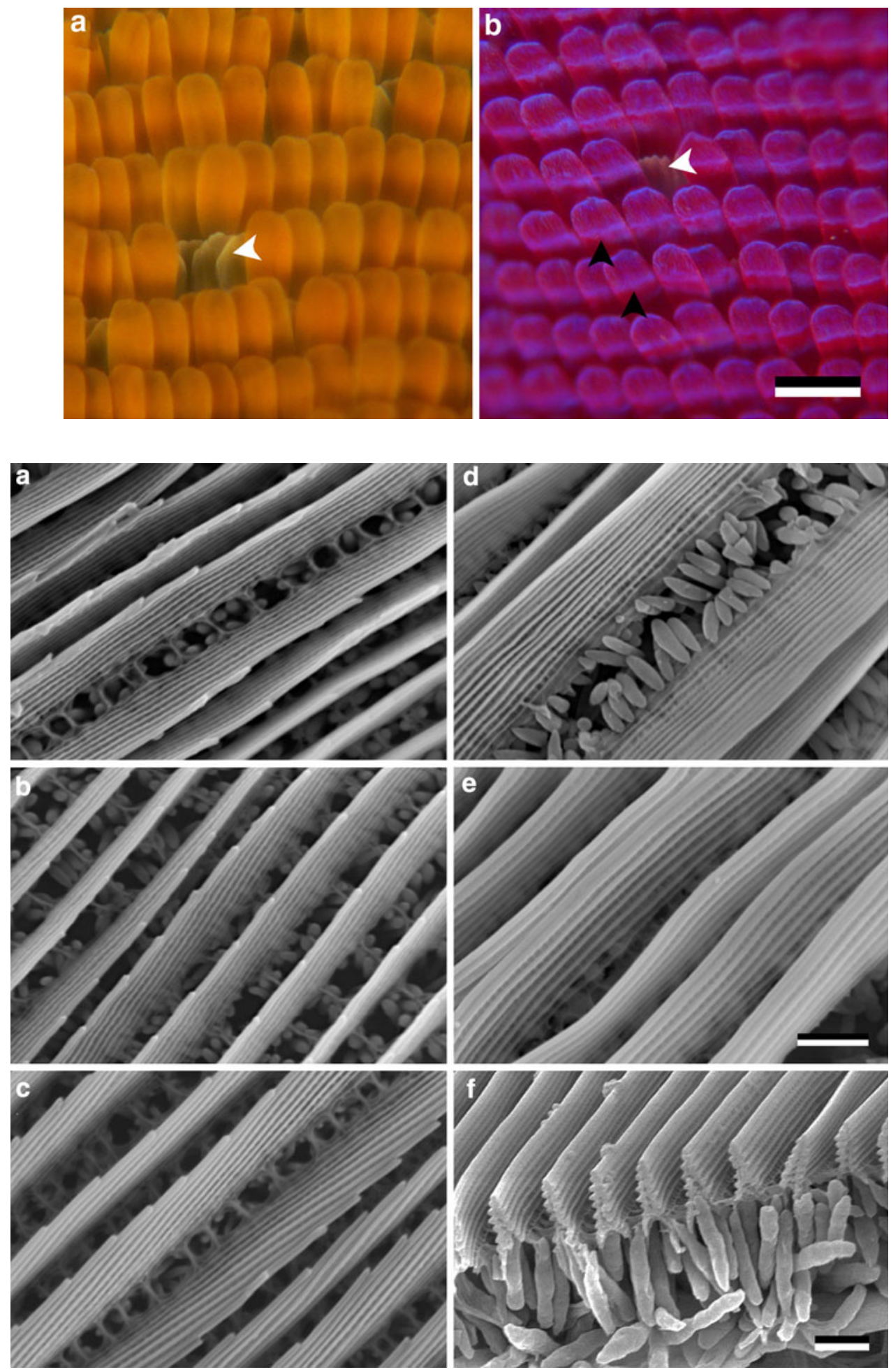

an objective with a limited aperture delivered the incident light and collected the backscattered light (Fig. 6). To obtain more detailed insight in the scale reflection characteristics, we measured the angle-dependent reflectance of the iridescent wing areas in a plane perpendicular to the wing surface and parallel to the local scale ridges. The investigated wing part was positioned at the cross-section of the measurement plane and the shared rotation axis of both illumination and measurement fibres. The angle of illumination was varied in discrete steps, and the detection angle was varied until a maximal signal for the shortwavelength reflection was obtained. For all investigated 
Table 1 Structural properties of the multilayer arrangement in the iridescent scales gained from electron microscopy

\begin{tabular}{|c|c|c|c|c|c|}
\hline Species & Number of layers, $N$ & Arrangement & Tilt angle & $d_{\mathrm{c}}(\mathrm{nm})$ & $d_{\mathrm{a}}(\mathrm{nm})$ \\
\hline G. cleopatra- $F W$ & $8-9$ & Tilted & $\sim 4-6^{\circ}$ & $58 \pm 5$ & $70 \pm 7$ \\
\hline G. cleopatra-HW & $6-7$ & Tilted & $\sim 4-6^{\circ}$ & $55 \pm 7$ & $76 \pm 6$ \\
\hline G. rhamni & $7-8$ & Tilted & $\sim 4-6^{\circ}$ & $62 \pm 5$ & $60 \pm 6$ \\
\hline H. glaucippe & $10-12$ & Parallel & $0^{\circ}$ & $59 \pm 6$ & $64 \pm 5$ \\
\hline C. regina & $6-7$ & Parallel & $0^{\circ}$ & $97 \pm 6$ & $98 \pm 6$ \\
\hline
\end{tabular}

$d_{\mathrm{c}}$ thickness of the cuticle layers, $d_{\mathrm{a}}$ thickness of the air layers (number of measurements $n>10$ )

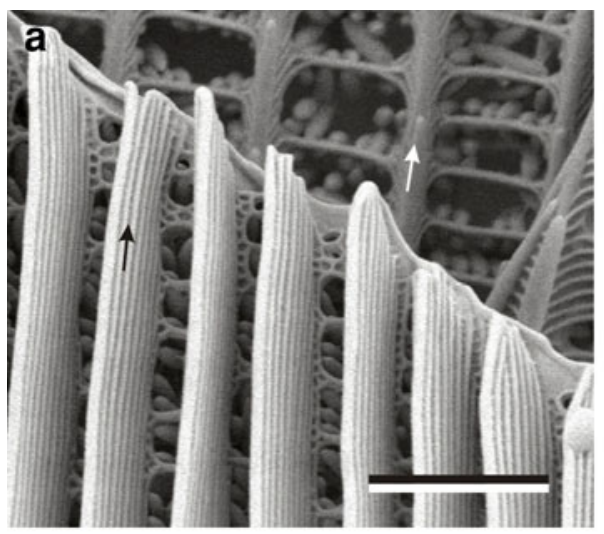

Fig. 4 Scale anatomy and reflectance of the wing tip of the Great Orange Tip, H. glaucippe. a Scanning electron micrograph of a cover scale, with slender ridges consisting of a stack of parallel lamellae (black arrow), overlying a ground scale, with undifferentiated ridges (white arrow) and the edge of another ground scale. The ridges of both scale types are connected by crossribs with pigment granules (bar $2 \mu \mathrm{m}$ ). b Diagram showing the three mechanisms that determine

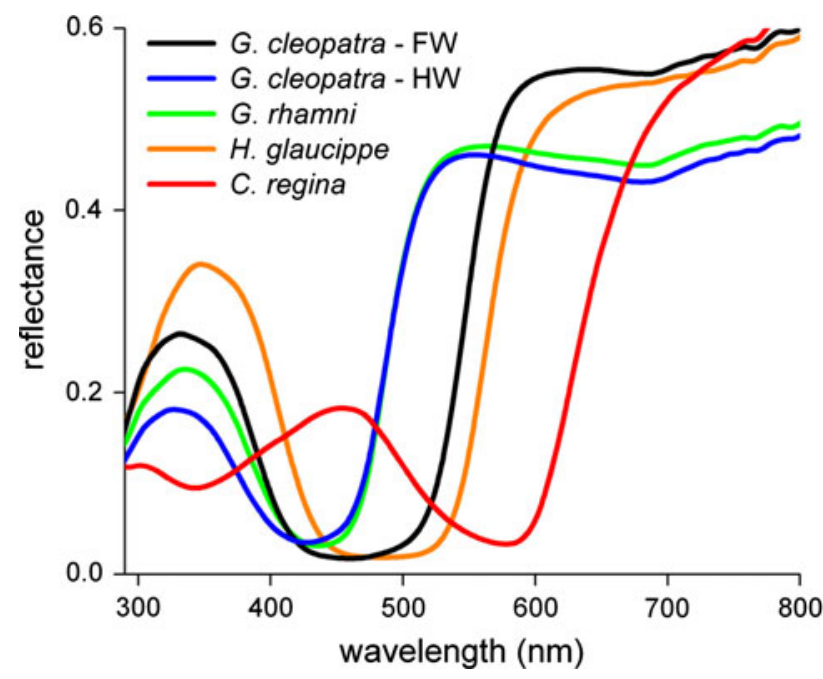

Fig. 5 Reflectance spectra of the iridescent wing areas of the pierid butterflies of Fig. 1, measured with an integrating sphere ( $F W$ forewing; $H W$ hindwing)

specimens, this resulted in an angle-dependency, which was mirror symmetric around a fixed offset-angle $(\alpha)$ where the angle of illumination and detection were identical.

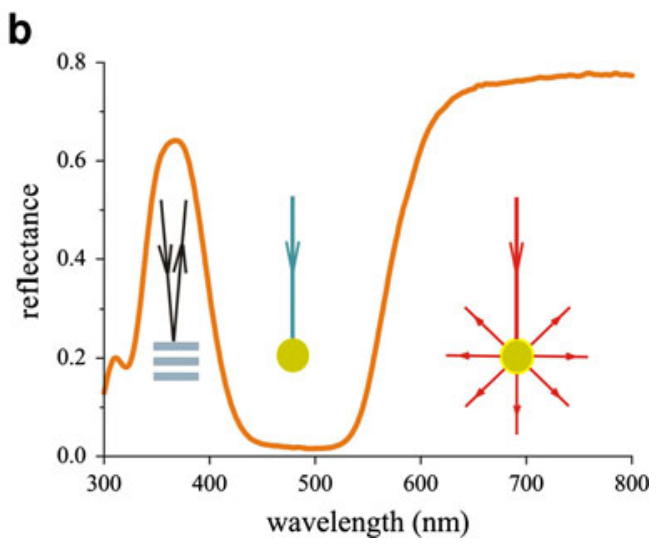

the reflectance spectrum of the wing tip. The multilayers of the cover scale determine the reflectance band in the (ultra)violet; the pigment granules absorb the light scattered in the short wavelength range, up to about $550 \mathrm{~nm}$; and the reflectance in the long wavelength range is determined by light scattering by the pigment granules and other scale components

Figure $7 \mathrm{a}, \mathrm{b}$ present the reflectance spectra obtained from H. glaucippe and C. regina. The spectral position of the short-wavelength bands progressively changed with increasing angle of light incidence, thus confirming that the wing tips of $H$. glaucippe and $C$. regina are iridescent. Figure 7c shows the dependence of the reflectance peak wavelength of the short-wavelength band on the angle of incidence. Estimation of the peak wavelengths was slightly ambiguous for $H$. glaucippe, because the short-wavelength reflectance band became multipeaked with increasing angle of incidence. Furthermore, the measurements became somewhat unreliable below $290 \mathrm{~nm}$. Nevertheless, in all studied species, the reflectance peak-wavelength showed a clear dependence on the angle of light incidence, very similar to that for multilayered structures, where the value of the reflectance peak wavelength is maximal for normal light incidence and decreases with increasing angle of incidence. However, the maximal peak wavelengths for $H$. glaucippe $(380 \mathrm{~nm})$ and C. regina $(480 \mathrm{~nm})$ were found for an offset-angle $\alpha$ of $-15^{\circ}$ and $-35^{\circ}$ against the wing normal, respectively (Fig. 7c; here a positive angle indicates a direction inclined towards the wing apex). Apparently, therefore, the lamellae of the cover scales have an 

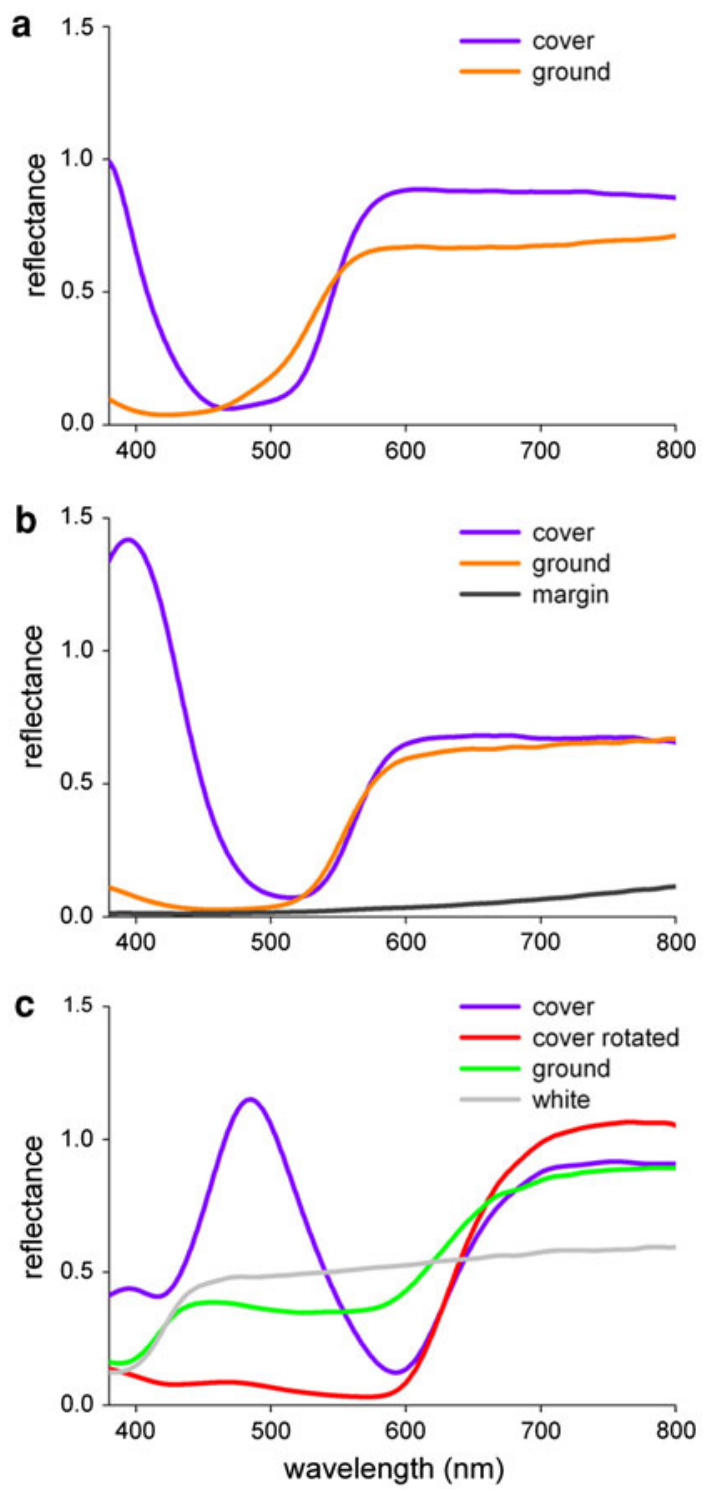

Fig. 6 Reflectance spectra of cover and ground scales of the iridescent wing areas, together with spectra from a few other scale types, measured with a microspectrophotometer. a $G$. cleopatra. The cover scale is orange, because of a pterin pigment, and it has in addition a reflectance peak in the UV, due to multilayered ridges. The ground scale is yellow-orange coloured, because of a slightly different pterin pigment composition. b $\mathrm{H}$. glaucippe. Cover and ground scale have the same pigmentation, but only the cover scale has a reflectance band in the violet. The brown scales in the wing margin (Fig. 1c) have a low reflectance throughout the visible wavelength range. The reflectance rise in the long-wavelength range is a clear sign of melanin pigment. c $C$. regina. The cover scale has a red colour due to a pterin pigment absorbing in most of the visible wavelength range and a blue colour due to the iridescent ridges, making together a purplish colour ('rotated' indicates that the cover scale was rotated away from the iridescence). The measured ground scale was located in the wing tip area where the cover scales were missing (see Fig. 2b). The ground scale itself was white, but the increased reflectance in the red, above $600 \mathrm{~nm}$, originated from red light scattered by the adjacent cover scales that was subsequently scattered by the white ground scale
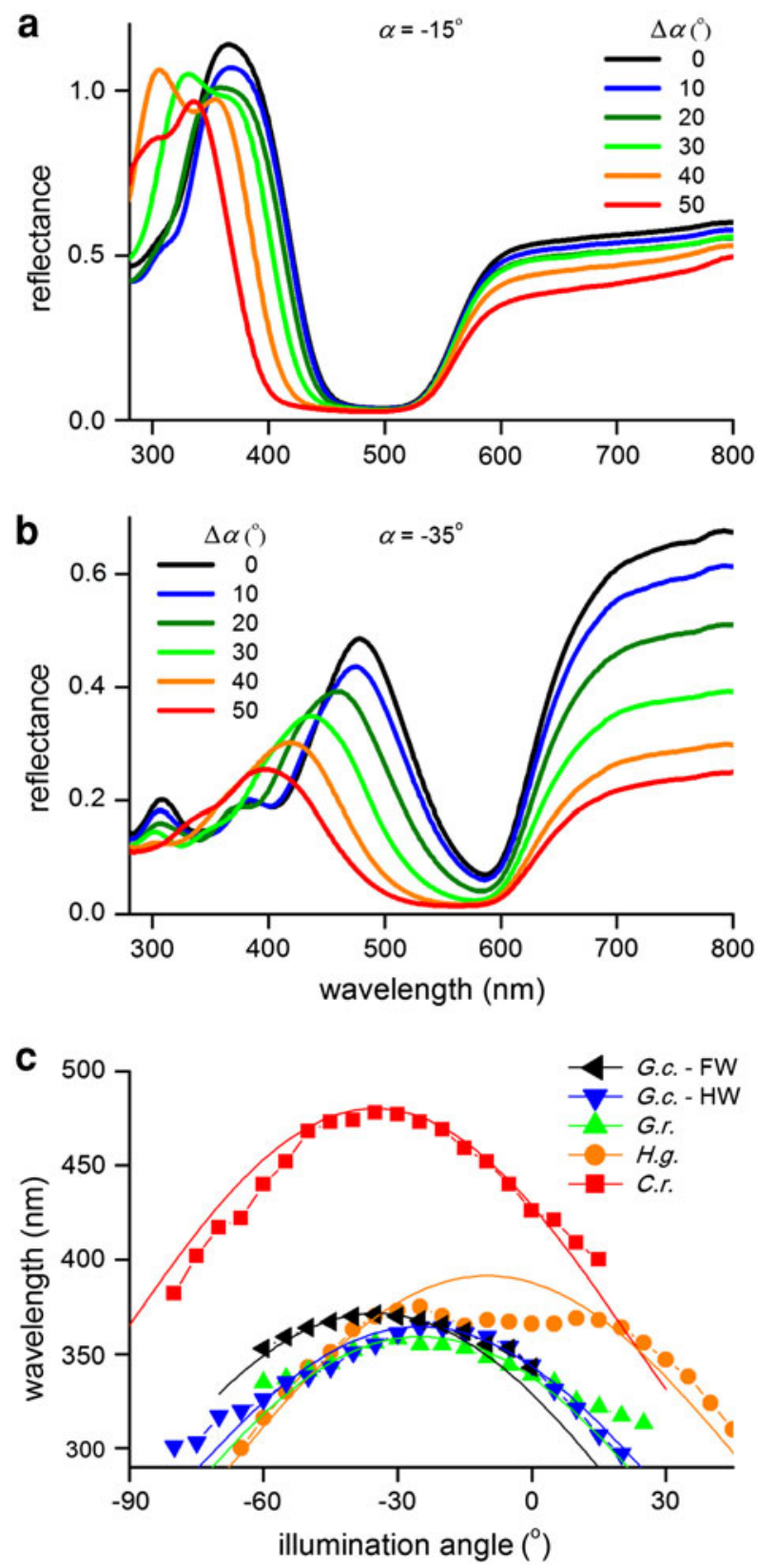

Fig. 7 Angle-dependent spectra showing iridescence. a H. glaucippe. $\alpha=-15^{\circ}$ indicates the angle of incidence where the UV-reflectance was maximal. $\Delta \alpha$ indicates the angle of incidence with respect to this direction of maximal reflectance. The UV-reflectance band shifts towards shorter wavelengths, as expected for a multilayer reflector. b $C$. regina. The blue reflectance band is maximal for an angle of incidence $\alpha=-35^{\circ}$. The dependence of the reflectance spectra on the angle of incidence is essentially identical to that of $H$. glaucippe. c Peak wavelength of the iridescence band as a function of angle of incidence, with negative angles signifying a tilt of the ridge multilayers towards the wing base. The values for $H$. glaucippe (orange circles) and C. regina (red squares) were derived from a and b. Similar measurements yielded the peak wavelengths for G. cleopatra (black left triangles, blue down triangles) and G. rhamni (green up triangles). The smooth curves are fits with the interference condition 
inclination angle of $15^{\circ}$ and $35^{\circ}$ with respect to the wing plane. Figure $7 \mathrm{c}$ also includes the dependence of the reflectance peak wavelength on the angle of incidence for the structurally coloured wing areas of the two Gonepteryx species.

Scale lamellae inclined with respect to the wing plane can be due to the scale being at an angle with respect to the wing surface and/or due to the scale multilayers being tilted at an angle with respect to the plane of the scale. The scanning electron micrographs of Fig. 3 show that the tilt angle between the lamellae and the scale surface differs among the species. In H. glaucippe (Fig. 3d) and C. regina (Fig. 3e), the lamellae run parallel to the surface of the scale. The inclination angles for these species of $15^{\circ}$ and $35^{\circ}$, respectively, concluded from the ARMs (Fig. 7c), hence must be due to tilting of the cover scales with respect to the wing plane. Visual inspection of the wings of the two species confirmed a clearly different-angled rooting of the scales in the wing plane for the two species. In G. cleopatra and $G$. rhamni, the lamellae are tilted with respect to the scale plane, with an angle of approximately $4-6^{\circ}$ (Table 1). Presumably the different structure of the ridges, i.e. parallel versus angled lamellae, is related to the different steepness of the iridescence curves for the different species of Fig. 7c.

The reflectance spectra of reflecting multilayers are determined by the refractive indices of the layers and their thicknesses. The reflecting ridges of the cover scales consist of layers of air and cuticle, which have refractive indices of $n_{\mathrm{a}}=1.0$ and $n_{\mathrm{c}}=1.56$, respectively (Vukusic et al. 1999). The layer thicknesses of the cover scale lamellae can be derived from the SEM data (Fig. 3). In the case of the blue-reflecting scales of $C$. regina, the thickness of the air layers was $d_{\mathrm{a}} \approx 100 \mathrm{~nm}$ and that of the cuticular layers was $d_{\mathrm{c}} \approx 95 \mathrm{~nm}$. In the lamellae of the cover scales of the other species, reflecting maximally in the UV, the thickness of the air and cuticular layers was $d_{\mathrm{a}} \approx 70 \mathrm{~nm}$ and $d_{\mathrm{c}} \approx 65 \mathrm{~nm}$, respectively. The interference condition for reflecting multilayers predicts how the reflectance peak wavelength depends on the layer thickness and the angle of light incidence: $\lambda_{\max }=2\left(n_{\mathrm{a}} d_{\mathrm{a}} \cos \theta_{\mathrm{a}}+n_{\mathrm{c}} d_{\mathrm{c}} \cos \theta_{\mathrm{c}}\right) ; \theta_{\mathrm{a}}$ and $\theta_{\mathrm{c}}$ are the angle of incidence at the layers, which are related to each other by Snell's law: $n_{\mathrm{a}} \sin \theta_{\mathrm{a}}=n_{\mathrm{c}} \sin \theta_{\mathrm{c}}$ (Land 1972; Kinoshita 2008). We have implemented the interference condition in Fig. 7c by using the above refractive indices and adjusting the anatomical data. Reasonable fits of the experimentally derived peak wavelengths with values following from the interference condition were obtained for $H$. glaucippe with $d_{\mathrm{a}}=d_{\mathrm{c}}=75 \mathrm{~nm}$, for C. regina with $d_{\mathrm{a}}=d_{\mathrm{c}}=93 \mathrm{~nm}$, for $G$. cleopatra $\mathrm{FW}$ with $d_{\mathrm{a}}=71 \mathrm{~nm}$ and $d_{\mathrm{c}}=65 \mathrm{~nm}$, for $G$. cleopatra $\mathrm{HW}$ with $d_{\mathrm{a}}=74 \mathrm{~nm}$ and $d_{\mathrm{c}}=67 \mathrm{~nm}$, and for $G$. rhamni with $d_{\mathrm{a}}=69 \mathrm{~nm}$ and $d_{\mathrm{c}}=71 \mathrm{~nm}($ Fig. 7c).
The peak reflectance of a multilayer increases with the number of layers. Figure 8 shows the maximal reflectance of the iridescence bands, derived from the integrated sphere spectra (Fig. 5), plotted as a function of the number of lamellae in the cover scale ridges, derived from SEM micrographs (Fig. 3), and fitted with a simple linear function. Such a simple connection might have been predicted when the area of the lamellae in the scales of the different species is the same. SEM data indeed suggests that the average width of the lamellae is approximately constant, $\approx 300 \mathrm{~nm}$.

\section{Discussion}

In this study, we have investigated the wing colours of the males of four pierid butterfly species. The wings contain pterin pigments responsible for pigmentary colouration, and the stacked lamellae of cover scales create structural colouration. The ridges act as iridescent reflectors, that is, the reflectance spectra shift to shorter wavelengths when the angle of light incidence increases. This phenomenon has been described before for a number of species of the pierid subfamily Coliadinae: Anteos clorinde, Eurema candida, E. hecabe and E. lisa (Ghiradella et al. 1972; Rutowski et al. 2007a). The wings of both male and female $A$. clorinde and $E$. hecabe have reflectance spectra with bands in the UV, also due to multilayered ridge lamellae, but in E. candida only males have iridescent wings. The reflectance spectra of the structural-coloured wings were shown to exhibit specific bands, and the dependence of the peak wavelength of the spectral bands on the angle of incidence was fitted with a linear function (Rutowski et al. 2007a). We have found here that the angle-dependence is cosine-like (Fig. 7c) and that it approximates the interference condition of multilayer reflectors.

The ridge lamellae of Morpho and pierid butterflies seem to behave as multilayers, but classical multilayer theory cannot be fully applied, of course, because the layer planes must then be large with respect to the light wavelength. In $H$. glaucippe and $C$. regina, the longitudinal dimension of the lamellae is certainly sufficiently large, but the width of the lamellae is much smaller than the light wavelength. This will result in considerable diffraction in a plane perpendicular to the longitudinal axis of the ridges. This phenomenon has been extensively studied in Morpho species (Vukusic et al. 1999; Kinoshita et al. 2002; Stavenga et al. 2009; Vukusic and Stavenga 2009).

In both the reflectance spectra measurements with the integrating sphere (Fig. 5) and the ARMs setup (Fig. 7a, b), the incident illumination was about normal to the wing surface, but the resulting spectra for $H$. glaucippe and $C$. regina were far from identical. The reason is that in the 


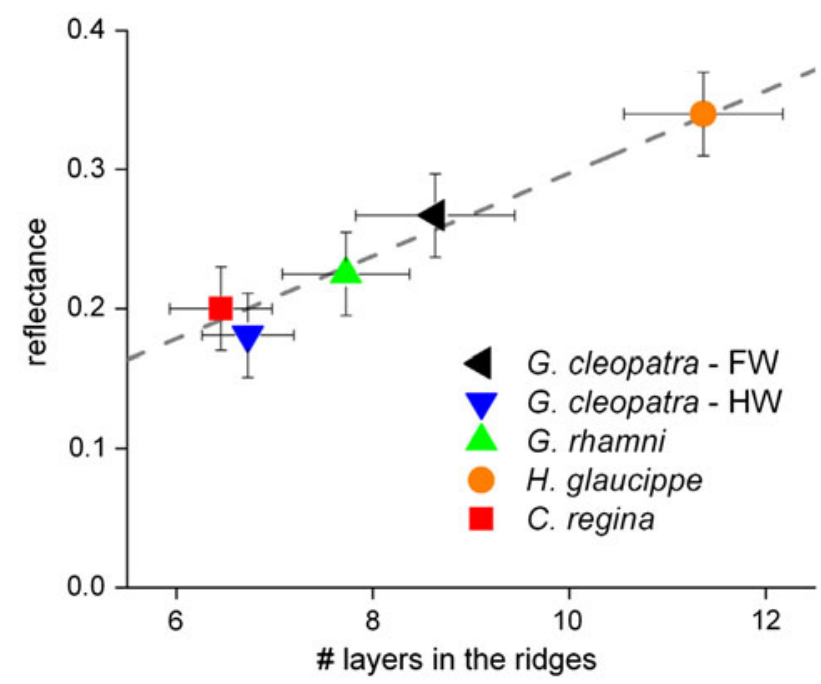

Fig. 8 Dependence of the peak integrated reflectance in the shortwavelength band, $R_{\max }$, on the number of layers in the ridges, $N$, fitted with a linear function: $R_{\max }=s N$, with slope $s=0.029$ (dashed line)

former case all hemispherically scattered light was measured, while in the latter case only light reflected in a rather small angle near the normal was captured. The spectra of the light diffracted into larger angular directions (that is, in the plane normal to the ridge axis) is increasingly shortwavelength shifted (not shown here, but see for this diffraction phenomenon in Morpho aega, Fig. 4c of Stavenga et al. 2009). The space averaged iridescence reflectance band of $C$. regina therefore peaks at about $460 \mathrm{~nm}$. Interestingly this value corresponds closely to the peak wavelength of blue-sensitive photoreceptors of pierid butterflies (Arikawa et al. 2005; Stavenga and Arikawa 2006; Wakakuwa et al. 2010).

Whereas in $C$. regina (and some other members of the Colotis group), the wing reflectance spectra have a bluepeaking spectral band (Wijnen et al. 2007; Giraldo et al. 2008), in virtually all studied species, the structural colouration bands are restricted to the UV (Ghiradella et al. 1972; Silberglied and Taylor 1973; Kemp et al. 2005; Rutowski et al. 2007a; Wijnen et al. 2007). The dominant presence of the UV-peaking reflectance bands suggests that a UV reflector creates a signal that strongly contrasts with that from common objects in the environment. The UV reflectance bands also seem to match well the sensitivity spectra of the UV photoreceptors of pierids, peaking at around $360 \mathrm{~nm}$ (Stavenga and Arikawa 2006; Pirih et al. 2010). Presumably, the structural colouration is designed to enhance the visibility for intraspecific chromatic signalling. As opposed to Morpho butterflies, which have a singlepeaked blue reflectance, most iridescent pierid butterflies seem to use the strategy of shifting the iridescence to the UV and complementing it with a diffuse yellow-red pigmentary colouration.
In the two Gonepteryx species as well as most other studied Coliadinae, the ridge lamellae are tilted with respect to the scale plane (Ghiradella et al. 1972). A notable exception is A. clorinde which has parallel lamellae (Rutowski et al. 2007a). Parallel lamellae were also shown for Eroessa chiliensis (Ingram and Parker 2008), a member of the tribe Anthocharidini, belonging to the pierid subfamily Pierinae (another member of the same tribe with iridescence is Anthocharis sara; Scott 1986). Iridescence is rare among the Pierinae, however (in preparation).

Colouration and visibility are essential for recognition of potential mates. Iridescence and the peak intensity of the created signal proved to be an important factor for mating success in the pierid Eurema hecabe (Kemp 2006) and also in the nymphalid Hypolimnas bolina (Kemp 2007). In the investigated pierids, the peak reflectance is proportional to the number of layers (Fig. 8). The structural colouration is most visible when seen from above, near the multilayer structure's normal. This normal can be tilted with respect to the scale's surface, which itself can be tilted with respect to the wing plane. The sum of the tilt angles can lead to a very restricted visibility of the butterflies, as was shown in Ancyluris meliboeus (Vukusic et al. 2002). The tilting thus will affect the visibility of the butterflies in nature.

Acknowledgments We thank H.L. Leertouwer for assistance and two anonymous referees for valuable comments. Financial support was given by EOARD/AFOSR grant FA8655-08-1-3012.

Open Access This article is distributed under the terms of the Creative Commons Attribution Noncommercial License which permits any noncommercial use, distribution, and reproduction in any medium, provided the original author(s) and source are credited.

\section{References}

Arikawa K, Wakakuwa M, Qiu X, Kurasawa M, Stavenga DG (2005) Sexual dimorphism of short-wavelength photoreceptors in the small white butterfly, Pieris rapae crucivora. J Neurosci 25:5935-5942

Braby MF, Vila R, Pierce NE (2006) Molecular phylogeny and systematics of the Pieridae (Lepidoptera: Papilionoidea): higher classification and biogeography. Zool J Linn Soc 147:239-275

Descimon H (1975) Biology of pigmentation in Pieridae butterflies In: Pfleiderer W (ed) Chemistry and biology of pteridines. De Gruyter, Berlin, pp 805-840

Ghiradella H (1989) Structure and development of iridescent butterfly scales: lattices and laminae. J Morphol 202:69-88

Ghiradella H (1998) Hairs, bristles, and scales. In: Locke M (ed) Microscopic anatomy of invertebrates, vol 11A: Insecta. WileyLiss, New York, pp 257-287

Ghiradella H (2010) Insect cuticular surface modifications: scales and other structural formations. Adv Insect Physiol 38:135-180

Ghiradella H, Aneshansley D, Eisner T, Silberglied R, Hinton HE (1972) Ultraviolet reflection of a male butterfly: interference color caused by thin-layer elaboration of wing scales. Science 178:1214-1217 
Gilbert LE, Forrest HS, Schultz TD, Harvey DJ (1988) Correlations of ultrastructure and pigmentation suggest how genes control development of wing scales of Heliconius butterflies. J Res Lepid 26:141-160

Giraldo MA (2008) Butterfly wing scales: pigmentation and structural properties. Thesis, University of Groningen

Giraldo MA, Yoshioka S, Stavenga DG (2008) Far field scattering pattern of differently structured butterfly scales. J Comp Physiol A 194:201-207

Ingram AL, Parker AR (2008) A review of the diversity and evolution of photonic structures in butterflies incorporating the work of John Huxley (The Natural History Museum, London from 1961 to 1990). Philos Trans Roy Soc B 363:2465-2480

Kemp DJ (2006) Ultraviolet ornamentation and male mating success in a high-density assemblage of the butterfly Colias eurytheme. J Insect Behav 19:669-684

Kemp DJ (2007) Female butterflies prefer males bearing bright iridescent ornamentation. Proc Roy Soc B 274:1043-1047

Kemp DJ, Rutowski RL (2007) Condition dependence, quantitative genetics, and the potential signal content of iridescent ultraviolet butterfly coloration. Evolution 61:168-183

Kemp DJ, Rutowski RL, Mendoza M (2005) Colour pattern evolution in butterflies: a phylogenetic analysis of structural ultraviolet and melanic markings in North American sulphurs. Evol Ecol Res $7: 133-141$

Kinoshita S (2008) Structural colors in the realm of nature. World Scientific, Singapore

Kinoshita S, Yoshioka S, Kawagoe K (2002) Mechanisms of structural colour in the Morpho butterfly: cooperation of regularity and irregularity in an iridescent scale. Proc Roy Soc B 269:1417-1421

Kinoshita S, Yoshioka S, Miyazaki J (2008) Physics of structural colors. Rep Progr Phys 71:076401

Land MF (1972) The physics and biology of animal reflectors. Progr Biophys 24:77-105

Mason CW (1926) Structural colors in insects. 1. J Phys Chem 30:383-395

Meadows MG, Butler MW, Morehouse NI, Taylor LA, Toomey MB, McGraw KJ, Rutowski RL (2009) Iridescence: views from many angles. J R Soc Interface 6:S107-S113

Morehouse NI, Vukusic P, Rutowski R (2007) Pterin pigment granules are responsible for both broadband light scattering and wavelength selective absorption in the wing scales of pierid butterflies. Proc Roy Soc B 274:359-366

Nijhout HF (1991) The development and evolution of butterfly wing patterns. Smithsonian Institution Press, Washington

Pirih P, Arikawa K, Stavenga DG (2010) An expanded set of photoreceptors in the Eastern Pale Clouded Yellow butterfly, Colias erate. J Comp Physiol A 197:501-517

Rutowski RL, Macedonia JM, Morehouse N, Taylor-Taft L (2005) Pterin pigments amplify iridescent ultraviolet signal in males of the orange sulphur butterfly, Colias eurytheme. Proc Roy Soc B 272:2329-2335

Rutowski RL, Macedonia JM, Kemp DJ, Taylor-Taft L (2007a) Diversity in structural ultraviolet coloration among female sulphur butterflies (Coliadinae, Pieridae). Arthropod Struct Dev 36:280-290

Rutowski RL, Macedonia JM, Merry JW, Morehouse N, Yturralde K, Taylor-Taft L, Gaalema D, Kemp DJ, Papke RS (2007b) Iridescent ultraviolet signal in the orange sulphur butterfly (Colias eurytheme): spatial, temporal and spectral properties. Biol J Linne Soc 90:349-364

Scott JA (1986) The butterflies of North America. Stanford University Press, Stanford

Silberglied R, Taylor OR (1973) Ultraviolet differences between the sulphur butterflies, Colias eurytheme and C. philodice, and a possible isolating mechanism. Nature 241:406-408

Stavenga DG, Arikawa K (2006) Evolution of color and vision of butterflies. Arthropod Struct Dev 5:307-318

Stavenga DG, Stowe S, Siebke K, Zeil J, Arikawa K (2004) Butterfly wing colours: scale beads make white pierid wings brighter. Proc Roy Soc B 271:1577-1584

Stavenga DG, Giraldo MA, Hoenders BJ (2006) Reflectance and transmittance of light scattering scales stacked on the wings of pierid butterflies. Opt Express 14:4880-4890

Stavenga DG, Leertouwer HL, Pirih P, Wehling MF (2009) Imaging scatterometry of butterfly wing scales. Opt Express 17:193-202

Stavenga DG, Giraldo MA, Leertouwer HL (2010) Butterfly wing colors: glass scales of Graphium sarpedon cause polarized iridescence and enhance blue/green pigment coloration of the wing membrane. J Exp Biol 213:1731-1739

Vukusic P, Sambles JR (2003) Photonic structures in biology. Nature 424:852-855

Vukusic P, Stavenga DG (2009) Physical methods for investigating structural colours in biological systems. J R Soc Interface 6:S133-S148

Vukusic P, Sambles JR, Lawrence CR, Wootton RJ (1999) Quantified interference and diffraction in single Morpho butterfly scales. Proc Roy Soc B 266:1403-1411

Vukusic P, Sambles JR, Ghiradella H (2000) Optical classification of microstructure in butterfly wing-scales. Photonics Sci News 6:61-66

Vukusic P, Sambles JR, Lawrence CR, Wootton RJ (2002) Limitedview iridescence in the butterfly Ancyluris meliboeus. Proc Roy Soc B 269:7-14

Wakakuwa M, Terakita A, Koyanagi M, Stavenga DG, Shichida Y, Arikawa K (2010) Evolution and mechanism of spectral tuning of blue-absorbing visual pigments in butterflies. PLoS One 5:e15015

Wijnen B, Leertouwer HL, Stavenga DG (2007) Colors and pterin pigmentation of pierid butterfly wings. J Insect Physiol 53:1206-1217

Wilts BD, Leertouwer HL, Stavenga DG (2009) Imaging scatterometry and microspectrophotometry of lycaenid butterfly wing scales with perforated multilayers. J R Soc Interface 6:S193S202

Yagi N (1954) Note of electron microscope research on pterin pigment in the scales of pierid butterflies. Annot Zool Jpn 27:113-114 